\title{
Development of High-Resolution Scintillator Systems
}

\author{
September 2007
}

\author{
Warnick Kernan \\ Larry Franks
}

Collaborators:

Arnold Burger and Michael Groza, Fisk University 


\section{DISCLAIMER}

This report was prepared as an account of work sponsored by an agency of the U.S. Government. Neither the U.S. Government nor any agency thereof, nor any of their employees, nor any of their contractors, subcontractors or their employees makes any warranty or representation, express or implied, or assumes any legal liability or responsibility for the accuracy, completeness, or usefulness of any information, apparatus, product, or process disclosed, or represents that its use would not infringe privately owned rights. Reference herein to any specific commercial product, process, or service by trade name, trademark, manufacturer, or otherwise, does not necessarily constitute or imply its endorsement, recommendation, or favoring by the U.S. Government or any agency thereof. The views and opinions of authors expressed herein do not necessarily state or reflect those of the U.S. Government or any agency thereof. 


\begin{abstract}
Mercuric iodide $\left(\mathrm{HgI}_{2}\right)$ is a well known material for the direct detection of gamma-rays; however, the largest volume achievable is limited by the thickness of the detector which needs to be a small fraction of the average trapping length for electrons. We report results of using $\mathrm{HgI}_{2}$ crystals to fabricate photocells used in the readout of scintillators. The optical spectral response and efficiency of these photocells were measured and will be reported. Nuclear response from an $\mathrm{HgI}_{2}$ photocell that was optically matched to a cerium-activated scintillator is presented and discussed. Further improvements can be expected by optimizing the transparent contact technology.
\end{abstract}




\section{CONTENTS}

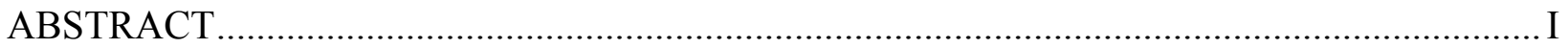

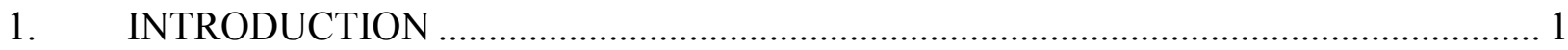

2. TECHNICAL APPROACH................................................................................... 1

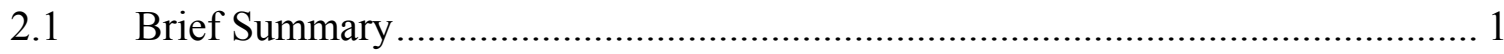

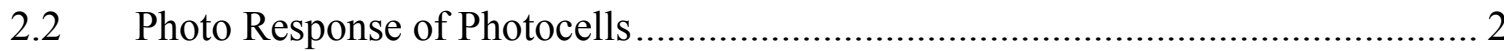

$2.3 \quad$ Scintillator/Photocell Convolutions ................................................................... 5

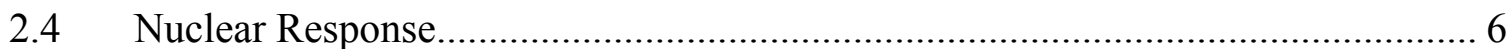

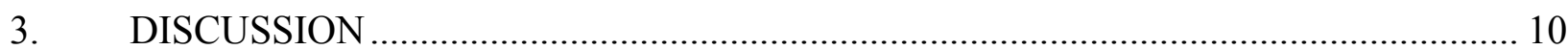

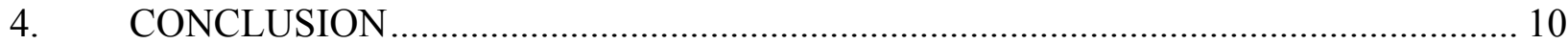

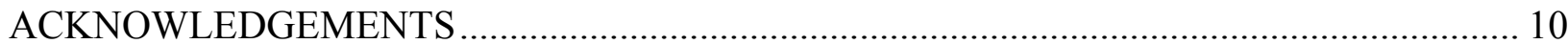

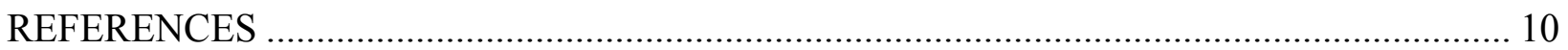




\section{INTRODUCTION}

Photomultiplier-based scintillator spectrometers are the systems of choice for a number of x-ray and gamma radiation measurement applications. They are commercially available in sizes sufficient to provide high-detection efficiency for the entire spectrum of gamma-ray energies of interest to the emergency response, national security, and nonproliferation communities. Despite this widespread use, they have numerous shortcomings. The most serious is the relatively poor energy resolution, which makes isotope identification problematic particularly where trace quantities are involved and where gamma-rays of similar energies are present. The inability to resolve closely spaced lines contributes to false alarms and reduces detection efficiency. Energy resolution in scintillator/photomultiplier tube (PMT) spectrometers is governed by a combination of the crystal intrinsic resolution, which includes non-linearity effects, photomultiplier statistics and transfer variance, and the variability in the probability of a scintillation photon generating a photoelectron at the photocathode. It is evident that energy resolution in these systems is linked to both the physics of light generation in the scintillator as a well as the characteristics of the PMT. PMTs also present design problems especially in the case of handheld and portable instruments due to their considerable weight and volume.

The goal of this project is to provide instrument-designers of scintillation based gamma-ray spectrometers with superior energy resolution and greatly reduced weight and volume. To achieve this advancement we planned to optimize the performance of a new class of inorganic scintillators by matching their emission spectra with the enhanced quantum efficiency (QE) of photocells. These new scintillators include $\mathrm{LaBr}_{3}: \mathrm{Ce}^{+3}$ (cerium-activated lanthanum tri-bromide) and $\mathrm{LaCl}_{3}: \mathrm{Ce}^{+3}$ (cerium-activated lanthanum tri-chloride) [1,2]. Photocells to be investigated include Si-PiN, $\left(\mathrm{HgI}_{2}\right)$, and $\mathrm{TlBr}$. The potential for improvements is illustrated by the case of the recent development of $\mathrm{LaBr}_{3}: \mathrm{Ce}^{+3}$ scintillators, which have provided the community with a material that has about three times better energy-resolution than typical NaI(Tl) PMT units. This dramatic result is due to very high conversion efficiency $(>60,000$ photons $/ \mathrm{MeV})$ and improved linearity. However, data indicate that the resolution has not been optimized. The substitution of a silicon avalanche photodiode (APD) for the PMT substantially improved resolution due primarily to the diode's higher $\mathrm{QE}$ in the spectral region of the peak of the cerium emission in $\mathrm{LaBr}_{3}$ lattice [3]. This was achieved with the APD cooled to $250 \mathrm{~K}$ to suppress noise. Cooling, however, is not considered an option in this study because the emphasis is on room temperature operation. This feature is of particular importance in portable instruments where low power consumption is required. While the temperature dependence of light emission in many scintillators is a problem, we note that $\mathrm{LaBr}_{3}$ is essentially free of this temperature dependence. Since other photodetectors with better matches to the cerium emission spectrum than PMTs are available, further improvements in resolution can be expected. $\mathrm{HgI}_{2}$ photocells, for example, have very high QE.

\section{TECHNICAL APPROACH}

\subsection{Brief Summary}

Apart from the saline contact $\mathrm{HgI}_{2}$ photocells, which were assembled at the Fisk Center for Photonic Materials and Devices, all photocells and scintillators were obtained from commercial sources. The $\mathrm{QE}$ of an $\mathrm{HgI}_{2}$ photocell was measured as a function of wavelength and compared 
to published data. Published emission spectra of the scintillators were convoluted with experimentally determined or published QE of the candidate photocells to guide the selection of the optimum scintillator-photocell pairings. Evaluations of the selected pairings were based on experimentally determined energy resolutions (at $662 \mathrm{keV}{ }^{137} \mathrm{Cs}$ ) obtained with radioactive sources and existing nuclear spectroscopy electronics. A TlBr photocell was also investigated. Material for the cell was obtained from Baltic Scientific and fabricated into a photocell at Fisk University. The bulk resistivity determined from an I-V plot was $4.8 \times 1010 \Omega \mathrm{cm}$.

Preliminary investigations revealed a number of photocells of possible interest to this project: $\mathrm{CdS}$, Se, SiC, GaN, GaP, GaAs, Si-PiN, Si-APDs, Si-drift, and $\mathrm{HgI}_{2}$. Few, however, have all of the requisite characteristics: high $\mathrm{QE}$ in the spectral region of interest, response time, size, and availability. For example, $\mathrm{CdS}$ and Se have useful spectral response, but the response times are too slow for this application. GaAs has adequate response time, but the spectral response is too far to the red. Si-APD and Si-drift devices have good spectral response but need cooling. Based on this preliminary work, $\mathrm{HgI}_{2}$ photocells appear to best suited for the advanced scintillators. In addition to $\mathrm{HgI}_{2}$, we investigated Si-PiN. The tests were confined to $\mathrm{LaBr}_{3}$ scintillators except a $\mathrm{CsI} / \mathrm{HgI}_{2}$ measurement, which was made to assess the performance of legacy $\mathrm{HgI}_{2}$ photocell [4, 5]. To provide a basis for comparison, the gamma-ray response of the $\mathrm{LaBr}_{3}$ scintillator was also measured with a bi-alkali cathode PMT. This baseline was considered necessary to remove any ambiguities that might arise from the known variations in the energy resolution of available $\mathrm{LaBr}_{3}$.

Based on these preliminary studies and component availability we confined our studies to the following photocell/scintillators combinations:

- $\mathrm{Si}-\mathrm{PiN} / \mathrm{LaBr}_{3}$

- $\mathrm{HgI}_{2} / \mathrm{LaBr}_{3}$

- $\mathrm{HgI}_{2} / \mathrm{CsI}$

- $\mathrm{TlBr} / \mathrm{LaBr}_{3}$

Commercially-available photocells were tested as received from vendors. Scintillators were attached directly to the cathodes using a thin layer of coupling grease (Bicron-630). Details of these measurements and the results follow.

\subsection{Photo Response of Photocells}

Since the only published QE information [4] on $\mathrm{HgI}_{2}$ photocells was nearly two decades old and obtained from different material with different fabrication techniques, the device under test was measured for comparison with the earlier data. The device under test was fabricated with a saline contact similar to that reported [5]. The cell was then fabricated from a $10 \mathrm{~mm} \times 10 \mathrm{~mm}$ $\mathrm{HgI}_{2}$ crystal $1.5 \mathrm{~mm}$ thick and shown in Figure 1. The test configuration is shown in Figure 2. The photocathode of the cell was illuminated with an Oriel lamp/monochromator (Model 74000) combination. Input optical power to the cell was monitored with an Oriel Power Meter (Model 70310). The output current of the cell was monitored with a Keithley Model 237 electrometer. We note that the test system was not capable of reaching wavelengths shorter than $400 \mathrm{~nm}$. 


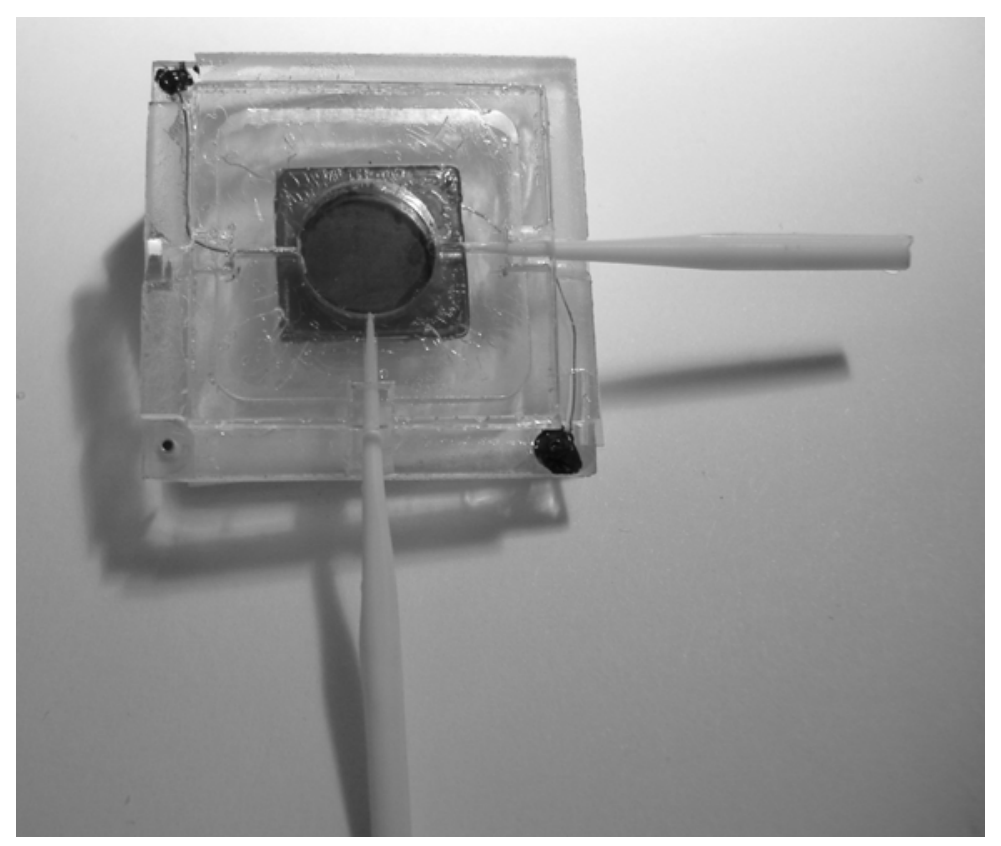

Figure 1. $\mathrm{HgI}_{2}$ photocell with saline contact.

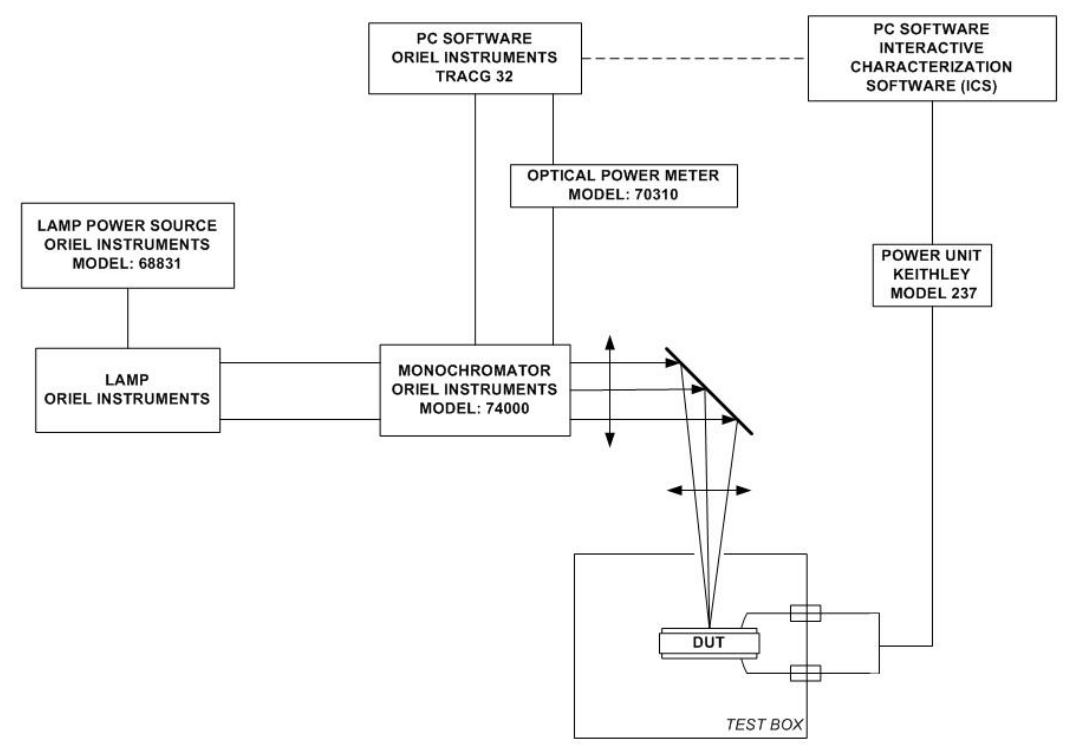

Figure 2. Schematic of the system used in this study for the measurement of QE.

The results of these measurements, together with the data of Reference 1, are shown in Figure 3. Good agreement with the referenced data is seen in the range 400 to $624 \mathrm{~nm}$. Using a different methodology, it is possible to make an estimate of the QE at wavelengths shorter than $400 \mathrm{~nm}$ by comparison of the direct response of $\mathrm{HgI}_{2}$ to radiation to the response of $\mathrm{HgI}_{2}$ to the light from the scintillator. This method yielded a significantly lower value of the $\mathrm{QE}$ in the region below $400 \mathrm{~nm}$ than the data of Figure 3, possibly due to less than optimal surface preparation and 
contacting of the photocell. It should be noted, however, that the bias voltage yielding the best QE does not necessarily produce the best nuclear response.

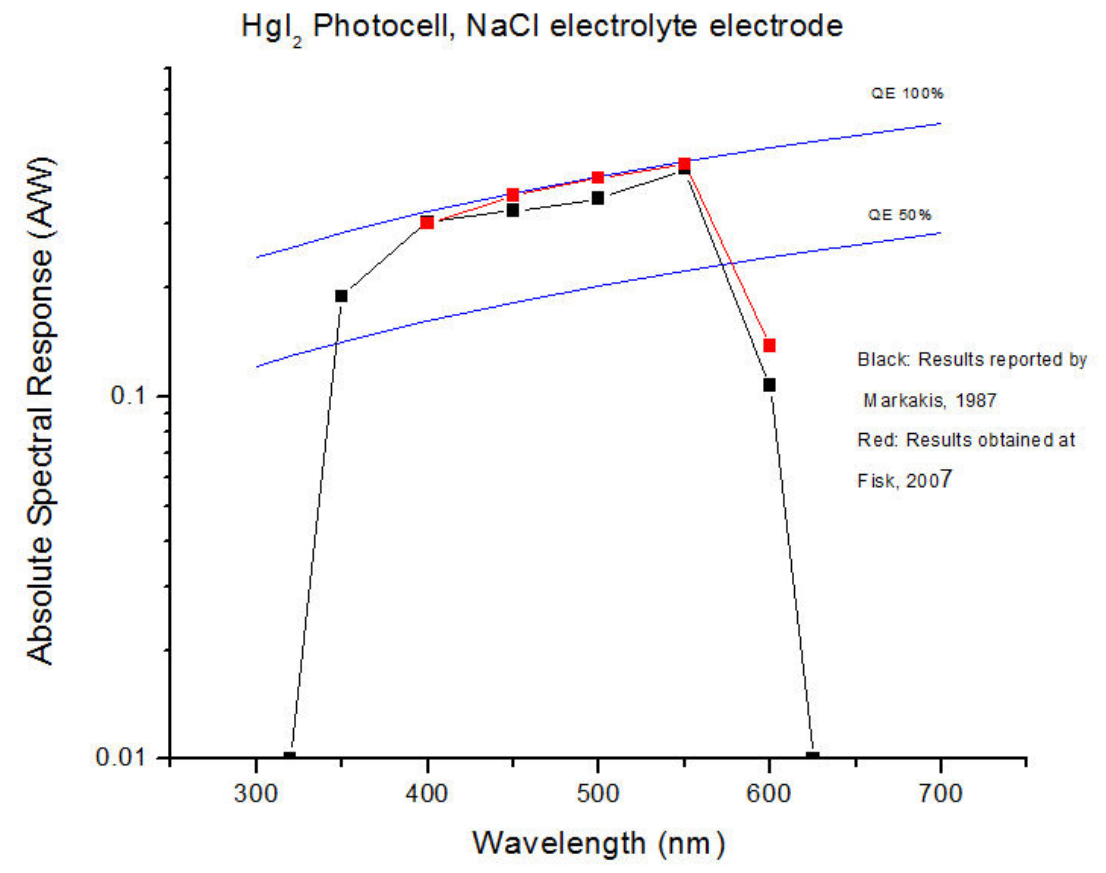

Figure 3. Photo response of $\mathrm{HgI}_{2}$ as reported by Markakis (black) and that obtained in this study (red).

The TlBr cell was fabricated from a $10 \times 10 \times 2.6 \mathrm{~mm}^{3} \mathrm{TlBr}$ crystal. The photocell had a transparent indium tin oxide (ITO) contact and a gold anode (Figure 4). The resistivity, as determined from an I-V plot, was $4.8 \times 10^{10} \Omega$-cm. The photocurrent, as a function of wavelength, was measured in the region 400 to $600 \mathrm{~nm}$ and is shown in Figure 5. One notes that the current falls precipitously at wavelengths shorter than the peak at $\approx 420 \mathrm{~nm}$ to very low values in the region of the $\mathrm{Ce}^{+3}$ emission. The photocurrent, while not precisely the $\mathrm{QE}$, is a good indicator of optical efficiency. 


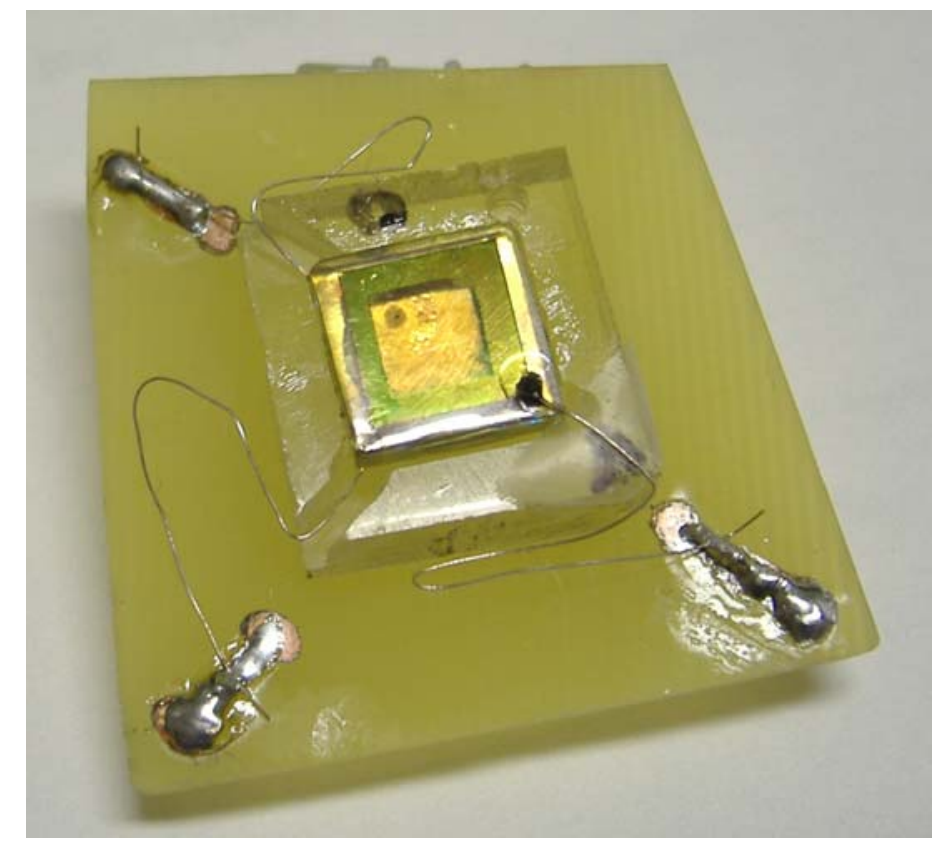

Figure 4. TIBr photocell (top view) with gold frame $(5 \times 5 \mathrm{~mm})$, TlBr $10 \times 10 \times 2.6 \mathrm{~mm}^{3}$.

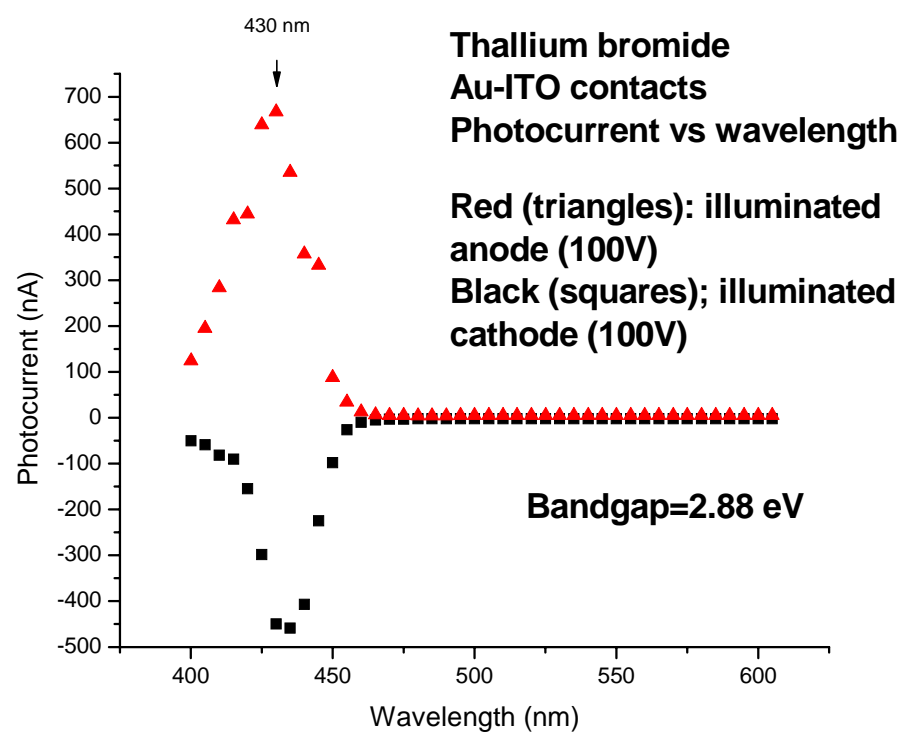

Figure 5. Photocurrents vs. wavelength in the region of 400 to $600 \mathrm{~nm}$.

\subsection{Scintillator/Photocell Convolutions}

As part of the selection process, qualitative estimates of the performance of a number of scintillators-photocell combinations, the emission spectrum of $\mathrm{LaBr}_{3}$ (provided by St. Gobain) was convoluted with the QE of the candidate photocells. The QE values shown in Figure 6 were taken from manufacturers' data sheet, except for $\mathrm{HgI}_{2}$, where the published data [4] was used. The results of the calculations are summarized in Table 1. 


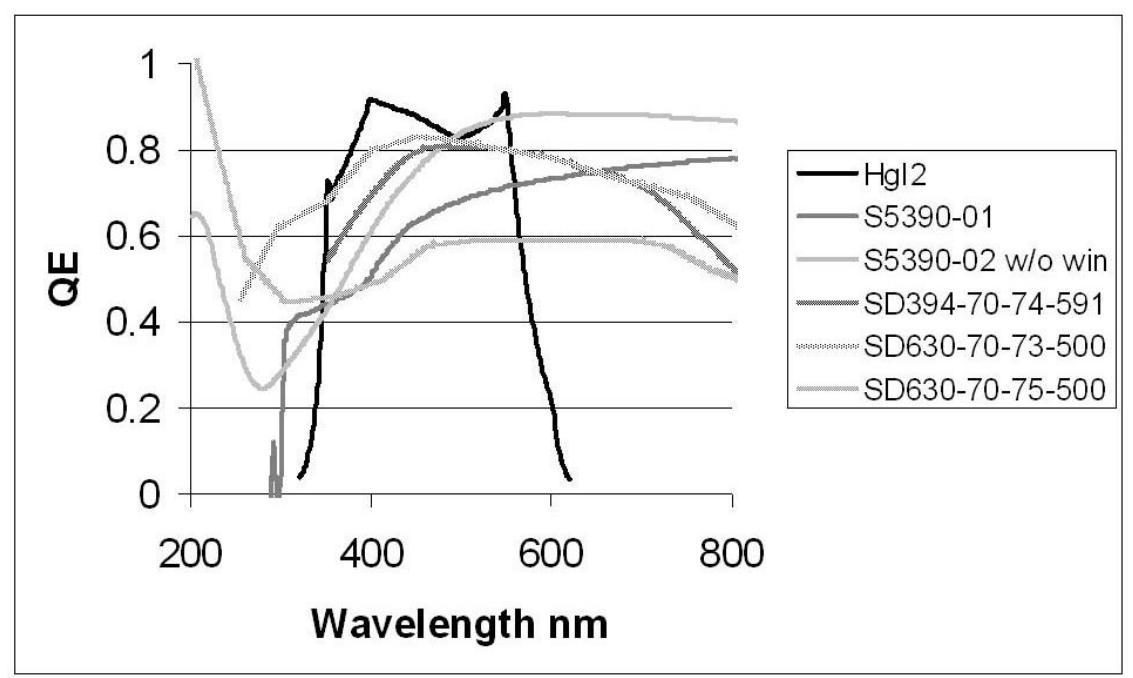

Figure 6. The QE of typical photocells compared with measured values of $\mathrm{HgI}_{2}$. The $\mathrm{HgI}_{2}$ values were from published data; other data were taken from the manufacturers' data sheets.

Table 1. Calculated figure of merit obtained from the Convolution of Scintillator Optical Emission Spectrum and Photocell QE.

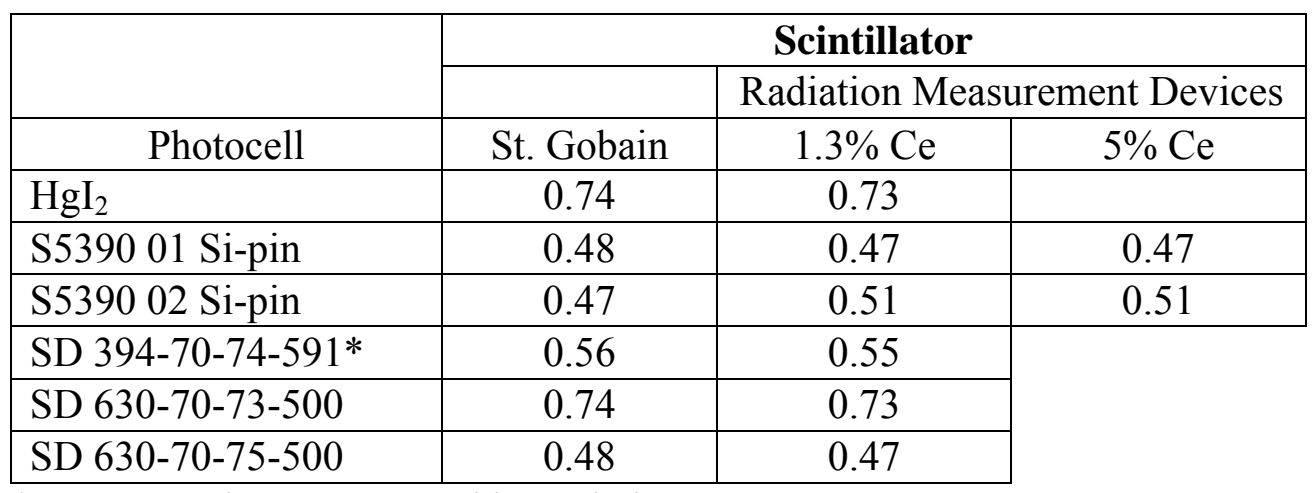

*Data started at $350 \mathrm{~nm}$ and is cooled $\mathrm{S}=$ Hammamatsu SI-PiN photodiodes $\mathrm{SD}=$ Advanced Photonix APDs

The Table 1 data indicate the two best candidates for coupling with $\mathrm{LaBr}_{3}$ are the $\mathrm{HgI}_{2}$ photocell and an uncooled APD (Advanced Photonix number SD 630-70-73-500). However, despite the good QE of this APD, electronic noise would likely degrade the resolution obtained with this device at room temperature.

\section{$2.4 \quad$ Nuclear Response}

The energy resolution of the scintillator/photocell combinations were measured with a $2 \mu \mathrm{Ci}$

${ }^{137} \mathrm{Cs}$ source placed on the scintillator. The test setup for the radiation measurements is shown in Figure 7. Note the preamplifier, in the foreground, is also in the test box. The test box isolated 
the scintillator/photocell from ambient light. A block diagram of the electronic system is shown in Figure 8.

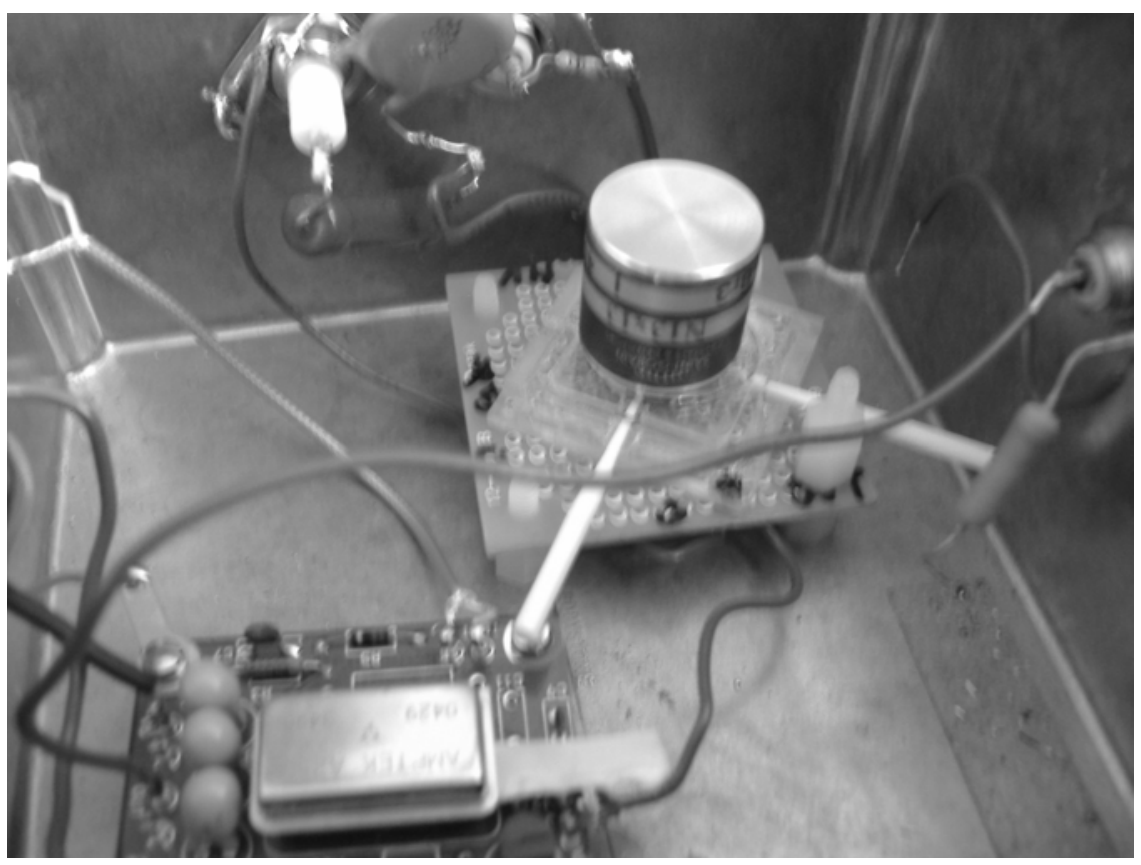

Figure 7. Test setup showing $\mathrm{LaBr}_{3}$ coupled to saline contact $\mathrm{HgI}_{2}$ photocell with preamplifier in the foreground.

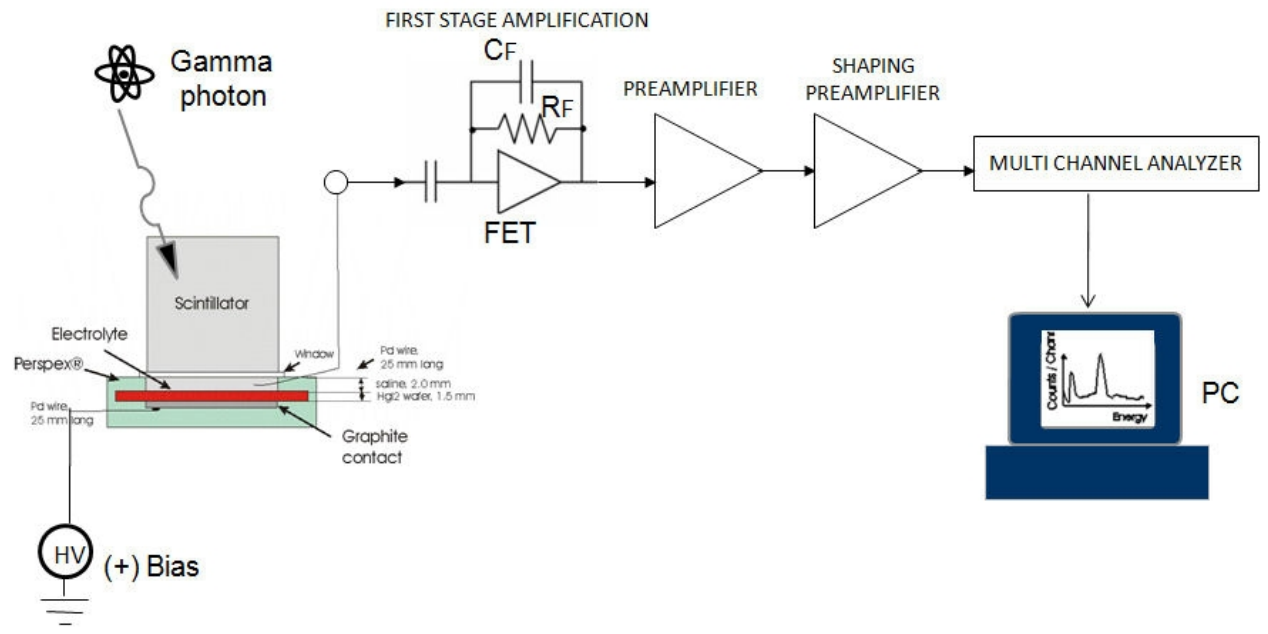

Figure 8. Block diagram of nuclear test electronics.

The spectra of a $\mathrm{LaBr}_{3}$ (right cylinder, $6 \mathrm{~mm}$ in diameter) detector coupled to a saline contact $\mathrm{HgI}_{2}$ photocell is shown in Figure 9. The overall energy resolution is $4.8 \%$ at $662 \mathrm{keV}\left({ }^{137} \mathrm{Cs}\right)$. The second peak is from a pulser and shows the electronic noise. The same scintillator achieved $3.5 \%$ resolution with a PMT and $13.7 \%$ with a Si-PiN diode (Hammamatsu S5390-02 windowless), Figures 10 and 11, respectively. The 6-mm diameter $\mathrm{LaBr}_{3}$ scintillator was coupled to the TLBr photocell and exposed to the Cs source. No discernable photo peak was observed, however, due presumably to poor QE of the cell in the spectral region of the $\mathrm{Ce}^{+3}$ emission. 


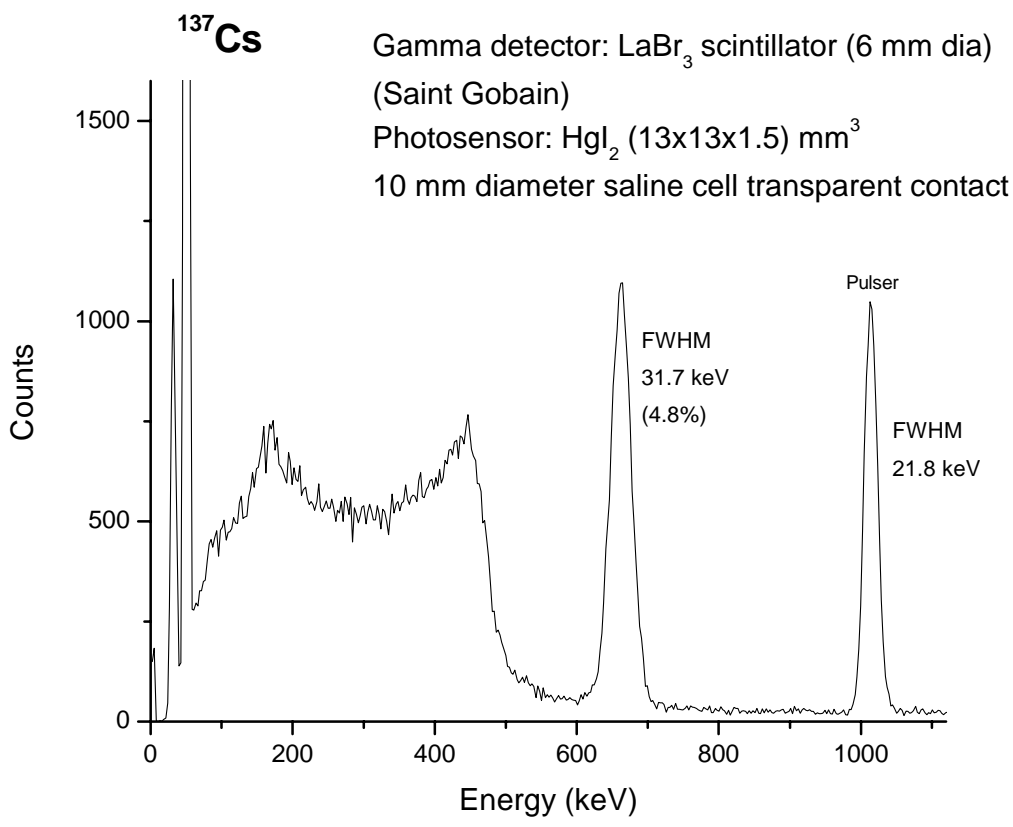

Figure 9. Spectral response of a $6 \mathrm{~mm} \mathrm{LaBr}_{3}$ coupled to a saline contact $\mathrm{HgI}_{2}$ photocell to a ${ }^{137} \mathrm{Cs}$ source. The second peak is from a pulser.

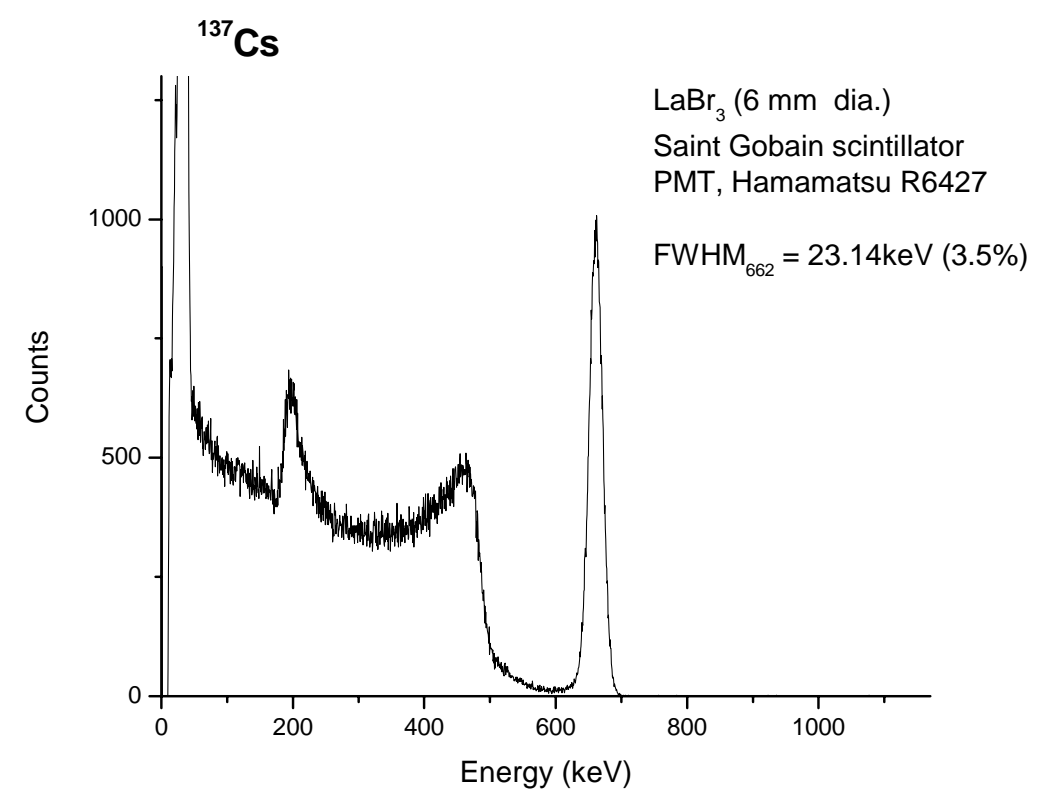

Figure 10. Response to $662 \mathrm{keV}\left({ }^{137} \mathrm{Cs}\right)$ by $\mathrm{LaBr}_{3}$ read with a PMT. 


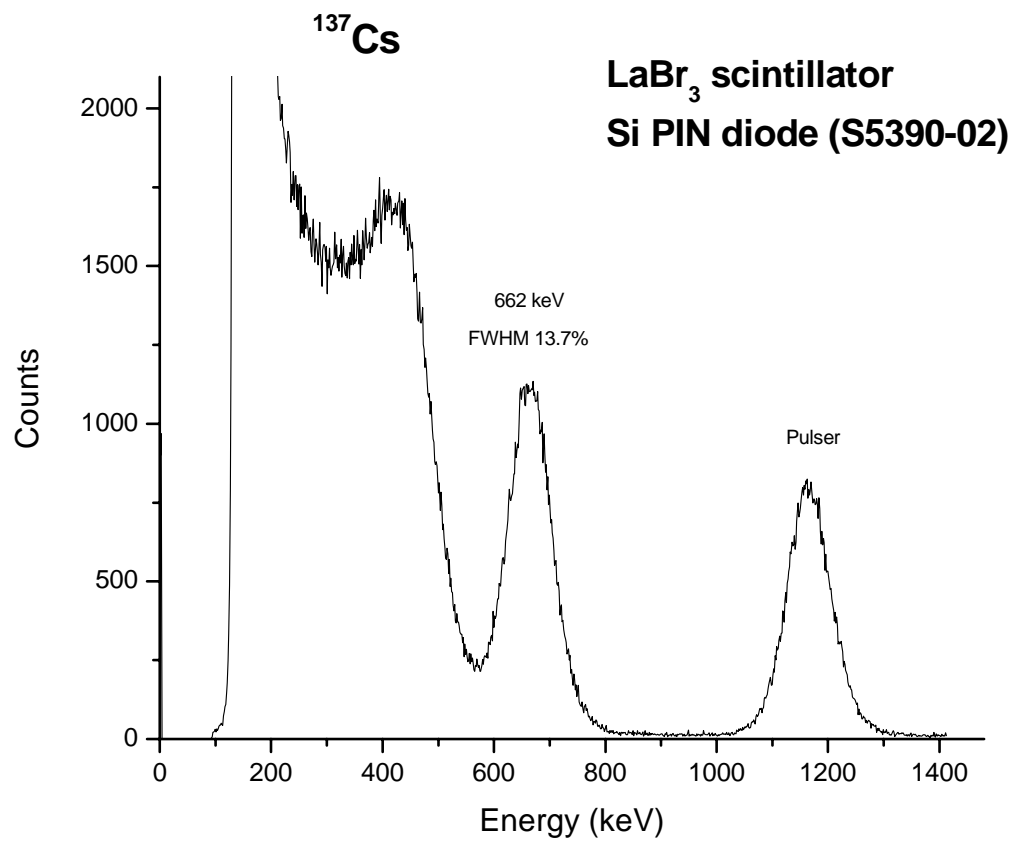

Figure 11. Response to $662 \mathrm{keV}\left({ }^{137} \mathrm{Cs}\right)$ by $\mathrm{LaBr}_{3}$ read with a Si-PiN diode without a window. 


\section{DISCUSSION}

The objective of this study was to demonstrate the feasibility of solid-state photocells as replacements for available PMTs used with scintillators. The chief candidates discussed in this report were $\mathrm{LaBr}_{3} \mathrm{Ce}^{3+}$ for the scintillator and $\mathrm{HgI}_{2}$ for the photocell. Significant progress was achieved in demonstrating high-resolution with a scintillator/photocell combination. Such a device promises a significantly smaller, lighter instrument for gamma-ray spectroscopy with reduced power requirements than can be achieved with PMTs. Note these results were achieved at room temperature.

Despite apparent QE greater than twice that of the PMT, the saline $\mathrm{HgI}_{2}$ cell achieved a slightly poorer resolution ( $4.8 \%$ vs. $3.5 \%$ ) than the PMT. Possible reasons for not achieving the desired result are that the $\mathrm{HgI}_{2}$ had either poor surface or bulk properties. Additionally, the optical coupling may have been sub-optimal, and there are electronic noise contributions as can be seen from Figure 9.

\section{CONCLUSION}

These results indicate that substituting photocells for a PMT will become an increasingly viable alternative for modest-sized scintillators. Large photocells will be noise limited because of capacitance. The use of pixels on larger photocells may allow for the use of this technique with larger scintillators. Also, new scintillators that emit at longer wavelengths (redder) will be even better candidates for use with photocells than lanthanum halides. $\mathrm{HgI}_{2}$ photocells remain a viable candidate for use with to $\mathrm{LaBr}_{3}$ scintillators, particularly if better contacting methods can be developed, and may be the best alternative to PMTs when room temperature operation is required.

\section{ACKNOWLEDGEMENTS}

We gratefully acknowledge conversations with Dr. Ludwig van den Berg of Constellation Technologies, Florida, and computational services provided by Scott Wilde of National Security Technologies, LLC. This work was supported by the U.S. Department of Homeland Security, Domestic Nuclear Detection Office, Office of Transformational Research and Development.

This work was done by National Security Technologies, LLC, under Contract No. DE-AC5206NA25946 with the U.S. Department of Energy.

\section{REFERENCES}

1. C. W. van Eijk, Phys. Med. Biol. 47, R85 (2002).

2. E. V. D. van Loef, et al., Nucl. Instru. Meth. Phys. Res. A 537, 232 (2005).

3. K. S. Shah, J. Glodo, M. Klugerman, W. M. Higgins, T. Gupta, and P. Wong, IEEE Transactions on Nuclear Science, Vol. 51, No. 5, 2395, (2004).

4. J. M. Markakis, Nucl. Instr. Meth. Phys. Res. A 263, 499, (1988).

5. J. M. Markakis, IEEE Transactions on Nuclear Science, Vol. 35, No. 1, 356, (1988). 